\title{
Temporal trends in adults' sports participation patterns in England between 1997 and 2006: the Health Survey for England
}

\author{
E Stamatakis, M Chaudhury
}

Department of Epidemiology and Public Health, University College London, London, UK

Correspondence to: Dr Emmanuel Stamatakis, Department of Epidemiology and Public Health, University College London, 1-19 Torrington Place, London WC1E 6BT, UK: e.stamatakis@ucl.ac.uk

Accepted 28 April 2008 Published Online First 25 July 2008

\section{ABSTRACT}

Objective: To examine temporal trends in participation in sport and exercise activities in England between 1997 and 2006 while taking into account wider societal changes.

Design: A series of annual cross-sectional surveys.

Setting and participants: Nationally representative samples of men $(n=27217)$ and women $(n=33$ 721) aged $\geqslant 16$ years.

Main outcome measures: Any (more than once every 4 weeks) and regular (more than once a week) participation in overall sport and exercise and a number of sport and exercise groupings (eg cycling, swimming, gym and fitness club-based activities (G/FC), racquet sports). Time point $(1997 / 98,2003 / 04,2006)$ was the main dependent variable.

Results: Age-standardised overall regular participation changed from $40.8 \%$ in $1997 / 98$ to $41.2 \%$ in 2006 for men (multivariable-adjusted participation $\mathrm{OR}=1.11$ in $2006,95 \% \mathrm{Cl} 1.03$ to $1.19, \mathrm{p}<0.001$ ) and from $31.2 \%$ to $33.9 \%$ for women $(1.21,1.13$ to $1.29, p<0.001)$. Regular $\mathrm{G} / \mathrm{FC}$ increased from $17.0 \%$ to $19.2 \%$ for men $(1.19,1.09$ to 1.30 ) and from $15.9 \%$ to $18.7 \%$ for women $(1.23,1.14$ to 1.33 ) and regular running increased from $2.4 \%$ to $4.0 \%$ for women only $(1.84,1.56$ to 2.18$)$. Overall increases were apparent only in older adults ( $\geqslant 45$ years) $(1.25$, 1.16 to $1.35, p<0.001)$. Young men (16-29 years) had reduced $\mathrm{ORs}$ for cycling $(0.72,0.58$ to $0.88, p=0.008)$, dancing $(0.60,0.45$ to $0.82, p=0.001)$, running $(0.78$, 0.64 to $0.94, p<0.001)$ and racquet sports $(0.60,0.42$ to $0.86, p=0.003)$. In men, increases were pronounced only among men from non-manual social classes, higher income households and white ethnic backgrounds.

Conclusions: Sports and exercise participation in England has changed between 1997 and 2006 as the result of increases among middle-aged and older adults and decreases among young men. There are no signs that the participation gap between less and more advantaged population groups is narrowing.

Regular physical activity is associated with decreased risk for many chronic conditions, including ischaemic heart disease, ${ }^{1}$ diabetes, ${ }^{2}$ certain types of cancer ${ }^{3}$ and obesity. ${ }^{4}$ Exercise and sports and are a subset of overall physical activity that are planned, structured and often have a competitive nature. Although recent public-health recommendations have placed an emphasis on moderateintensity activities, such as brisk walking and intense housework, ${ }^{5}$ more vigorous sports and exercise confer greater health protection. ${ }^{6}$ Furthermore, sports participation not only optimises the advantages to physical health but is associated with enhanced social well-being, general sense of belonging, ${ }^{78}$ lower unemployment, less crime and stronger community cohesion. ${ }^{9}$ For all these reasons, increasing the levels of sports participation in the UK has moved up the political agenda. In a recent government report, the importance of sports development and social inclusion for different population groups was highlighted, along with greater access to sports facilities in the community, through the investment of $£ 1.5-£ 2$ billion via local authorities over the decade to 2010. Major efforts to monitor sports participation include the Sport England-funded Active People survey, ${ }^{10}$ which has been recruiting a sample of $>350000$ English adults every 3 years since 2005, further evidence of the commitment of the promotion of "grassroots" sports participation.

To date, information on temporal trends in sports participation in England has come from population surveys, such as the General Household Survey (GHS) ${ }^{11}$ and the Health Survey for England (HSfE). ${ }^{12}$ The GHS found that between 1996 and 2002 , overall sports participation dropped but it is uncertain whether this finding reflects actual participation or is the result of changes in the GHS measuring instrument. In addition no published report on sport participation has taken into account wider sociodemographic changes and it is therefore not possible to determine whether any changes are "true" or whether they simply reflect other population trends in factors that influence sports participation. Such changes include increases in mean age and life expectancy, obesity rates, disposable income, and non-white ethnic minority groups. For instance, the decline in participation reported by GHS may have more to do with the increase in adult obesity ${ }^{12}$ and the rapid ageing of the population than to a true decline in participation. Furthermore, despite the belief in some quarters that participation in physical activity and sport is declining, ${ }^{5}$ a previous report showed that there have been increases in adult sports participation between 1991 and 2003/04 in England. ${ }^{13}$ The present work expands on and updates this work by presenting a detailed analysis of overall participation and of participation in specific recreational sports and structured exercise between 1997 and 2006.

The main aim of the paper is to investigate temporal trends in adult sports participation and the participation patterns in England over the decade 1997-2006, taking into account wider socioeconomic, demographic and behavioural changes. Such information will help to evaluate recent physical activity and sports-promoting 
Table 1 Participation frequencies in sport and exercise activities groupings used in the present study

\begin{tabular}{|c|c|c|c|c|}
\hline \multirow[b]{3}{*}{ Grouping and components } & \multicolumn{4}{|c|}{ Component frequency } \\
\hline & \multicolumn{2}{|l|}{ n } & \multicolumn{2}{|l|}{$\%$} \\
\hline & Men & Women & Men & Women \\
\hline Cycling (any purpose) & 4027 & 2446 & 14.8 & 7.3 \\
\hline Swimming & 3467 & 5157 & 12.7 & 15.3 \\
\hline Dancing & 1600 & 3570 & 5.9 & 10.6 \\
\hline Running & 2929 & 1557 & 10.8 & 4.6 \\
\hline \multicolumn{5}{|l|}{ Team sports } \\
\hline Football/rugby & 3151 & 250 & 11.6 & 0.7 \\
\hline Basketball & 18 & 0 & $<0.1$ & NA \\
\hline Netball/handball & 4 & 143 & $<0.1$ & 0.4 \\
\hline Volleyball & 55 & 23 & 0.2 & 0.1 \\
\hline Polo & 2 & 1 & $<0.1$ & $<0.1$ \\
\hline Hockey & 51 & 55 & 0.2 & 0.2 \\
\hline Baseball/softball & 10 & 5 & $<0.1$ & $<0.1$ \\
\hline Cricket & 253 & 20 & 0.9 & 0.1 \\
\hline Lacrosse & 3 & 5 & $<0.1$ & $<0.1$ \\
\hline \multicolumn{5}{|l|}{ Racquet sports } \\
\hline Badminton/tennis & 1082 & 900 & 4 & 2.7 \\
\hline Squash & 545 & 148 & 2 & 0.4 \\
\hline Table tennis & 83 & 53 & 0.3 & 0.2 \\
\hline Racquetball & 2 & 1 & $<0.1$ & $<0.1$ \\
\hline \multicolumn{5}{|l|}{ Martial arts } \\
\hline Boxing & 42 & 4 & 0.2 & $<0.1$ \\
\hline Any other martial art & 156 & 100 & 0.6 & 0.3 \\
\hline Golf & 1442 & 258 & 5.3 & 0.8 \\
\hline \multicolumn{5}{|l|}{ Gym/fitness club-based } \\
\hline Gym workout, weight training, keep-fit & 3722 & 3544 & 13.7 & 10.5 \\
\hline Calisthenics & 4087 & 4058 & 15 & 12 \\
\hline Aerobics & 748 & 3437 & 2.7 & 10.2 \\
\hline \multicolumn{5}{|l|}{ Outdoor watersports } \\
\hline Canoeing & 46 & 29 & 0.2 & 0.1 \\
\hline Sailing & 79 & 31 & 0.3 & 0.1 \\
\hline Rowing & 42 & 19 & 0.2 & 0.1 \\
\hline Surfing & 38 & 9 & 0.1 & $<0.1$ \\
\hline Wind-surfing & 21 & 8 & 0.1 & $<0.1$ \\
\hline Scuba diving & 20 & 17 & 0.1 & 0.1 \\
\hline
\end{tabular}

NA, non-applicable.

Data collected from men $(n=27213)$ and women $(n=33721)$ participating in the Health Survey for England in 1997, 1998, 2003, 2004 and 2006.

interventions and policies and may identify population subgroups in need of tailored interventions to boost sports participation.

\section{METHODS}

Ethics approval was granted by the London multicentre research ethics committee.

\section{Sample}

We used HSfE ${ }^{12}$ data collected in 1997, 1998, 2003, 2004 and 2006. The HSfE is a continuous survey that draws annually from a nationally representative general population sample of adults living in households. Up to 10 adults were interviewed in each household. The sample is drawn using multistage stratified probability sampling with postcode sectors as the primary sampling unit and the Postcode Address File as the sampling frame for households. Stratification was based on geographical areas rather than on individual characteristics of the population.

\section{Measurements}

Data were collected by interviewers during household visits and questions enquired about age, sex, ethnicity, social class, income, education, smoking habits, self-reported health, car ownership and physical activity. The interviewers also measured height using stadiometers (Chasmors Ltd., London, UK) and weight using electronic digital scales (Tanita Inc., Tokyo, Japan). ${ }^{12}$ Body mass index (BMI) was calculated as weight divided by the squared height. Sport and exercise participation was measured by showing respondents a card listing common activities such as swimming, cycling, gym workout, aerobics, keep-fit, dancing, running/jogging, football/rugby, badminton/ tennis, squash and calisthenics. Respondents were asked if they had taken part in any of these and up to four other activities in the 4 weeks before the interview. Additional questions investigated the frequency and typical duration of each session of sport and exercise. Other questions probed for participation in non-sport and exercise physical activity, such as walking, intense domestic activity (eg heavy housework) and occupational physical activity. More details on the physical activity 
Table 2 Characteristics of the sample by survey year

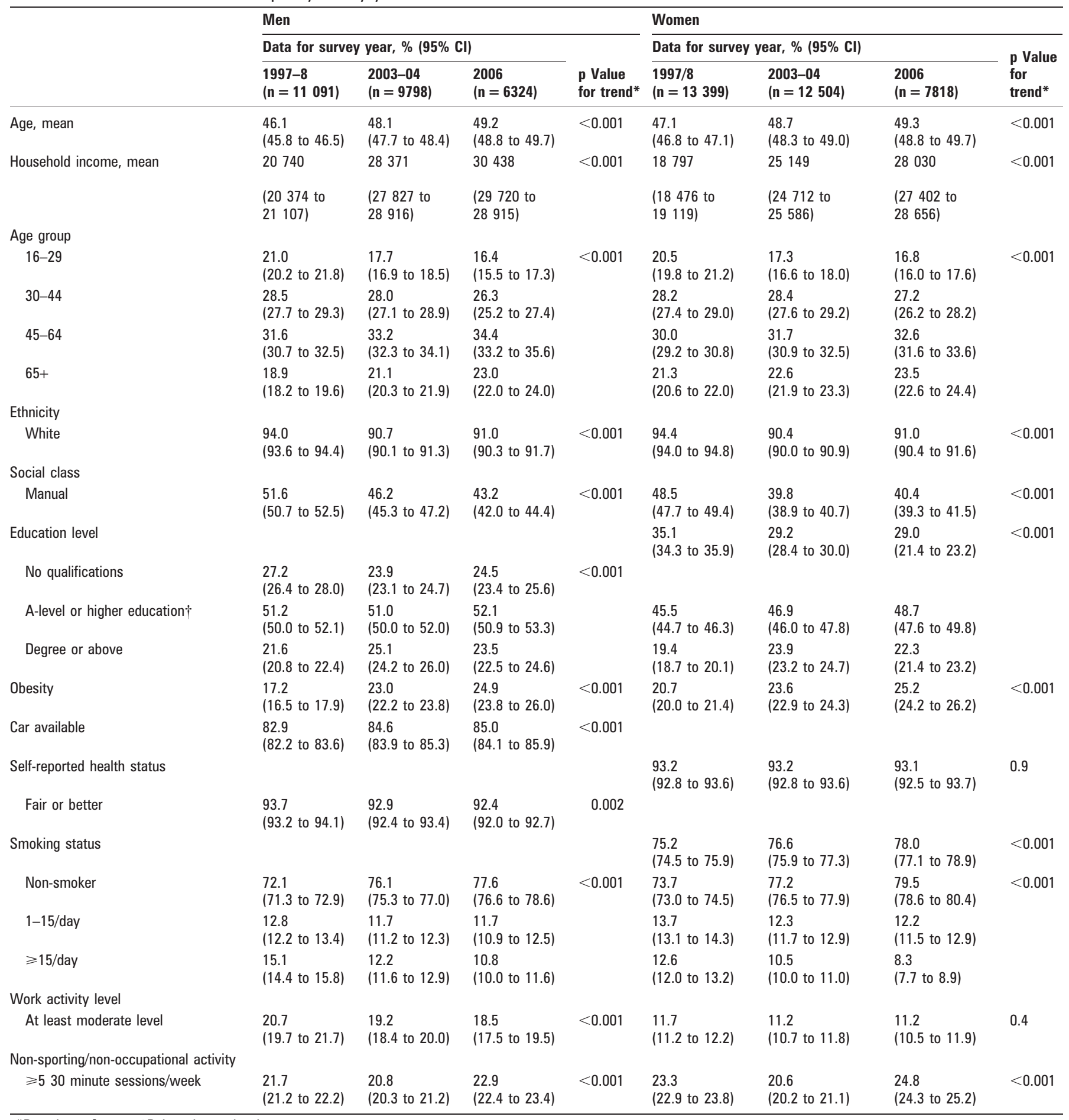

*Based on $\chi^{2}$ tests. †Below degree level.

Data from the Health Survey for England, men and women aged $\geqslant 16$ years.

measuring methodology have been published previously. ${ }^{12} 14$ The criterion validity of the physical activity questions is supported by a recent study on 106 general population English adults (45 men) where the output of an accelerometer worn for two non-consecutive weeks was compared against the output of the above questionnaire (our unpublished observations, manuscript in preparation). Intraclass correlation coefficients for time spent in moderate to vigorous physical activity were 0.47 for men $(p=0.03)$ and 0.43 for women $(p=0.02)$. The test-retest reliability coefficients of the same variable were 0.89 for men $(p<0.001)$ and 0.76 for women $(p<0.001)$. Additionally, the sport and exercise section of the questionnaire has been shown to have excellent convergent validity in grading a plethora of biochemical and physiological CVD risk factors. ${ }^{15}$ The measuring method was identical across survey years and the research was carried out by the same organisations and workforce.

\section{Sport and exercise grouping}

Swimming, dancing, cycling and running were considered individually, all other sport and exercise were grouped. Table 1 
shows how sport and exercise were grouped for this analysis and the percentage contribution of each individual sport and exercise.

\section{Statistical analyses}

We initially calculated age-standardised sport and exercise participation rates and 95\% CI by time point (1997/98 combined, 2003/04 combined and 2006). Age standardisation was performed using the mid 2005 English population estimates (5-year bands) as a reference. Further statistical analyses were data-driven. In the first step, we merged all HSfE years to examine the univariable correlations between sport and exercise and number of potential sport and exercise correlates (sex, age, ethnicity, social class, BMI, area type, general health, number of cars, marital status, car ownership, occupational physical activity and non-sporting physical activity) using the $\chi^{2}$ test. The $\chi^{2}$ test was then used to examine the crude time trends for those variables that presented significant univariable correlations with sport and exercise in the first step. In the third step, we developed several sex-specific multiple logistic regression models, in which sport and exercise participation was the dependent variable. Sport and exercise participation covered any participation (at least once in the previous 4 weeks in any sport and exercise grouping), regular participation (at least once a week in any sport and exercise grouping) and any and regular participation in each sport and exercise grouping. The key independent variable in these logistic regression models was time point, and the covariates entered into these models were all these factors that showed changes over time in step 2. Time trends in regular sport and exercise by age group (16-29, 30-44, $45-64$, $\geqslant 65$ years), social class (manual vs non-manual) and ethnicity (white vs non-white) were also examined using multivariate-adjusted logistic regression. In all logistic regression models, OR and 95\% CI calculated in relation to 1997/98, which served as the referent time point. We also calculated time trends in weekly sport and exercise volumes (number of sessions $\times$ duration of each session) of participants for total and for each sport and exercise grouping. We tested this trend using linear regression adjusted for age, sex and social class.

\section{RESULTS}

The sample comprised 60938 adults (27 217 men). Response rates were $71 \%$ in $1997 / 8$, 66\% 2003/04 and $61 \%$ in 2006 . The mean (SD) number of adults per household remained stable over time: 2.2 (0.9) in 1997/8, 2.1 (0.9) in 2003/04 and 2.1 (0.9) in 2006. When all surveys were combined, factors associated inversely with overall sport and exercise participation for men were age and BMI (both $\mathrm{p}<0.001$ ), and factors that correlated positively were social class, household income, education, general health status, car ownership, non-sporting/non-occupational physical activity and occupational physical activity level (all $\mathrm{p}<0.001)$. Factors associated inversely with participation for women were age, BMI (both $\mathrm{p}<0.001$ ) and ethnicity (higher participation among whites, $\mathrm{p}<0.001$ ), and positive associations were found for social class, household income, education, general health, car ownership, non-sporting/non-occupational physical activity and occupational physical activity level (all $\mathrm{p}<0.001$ ).

As shown in tables 2 and 3, between 1997/8 and 2006 there were significant increases in average age, average household income, obesity, non-smoking, car ownership and non-sporting/ non-occupational activity ( $\geqslant 5$ sessions/week) for both men and women. Conversely, there were decreases in the percentage of men and women belonging to manual social classes, with no education qualification, who smoked at least 15 cigarettes a day and who were of white ethnic origin. In addition, there were decreases in the rates of men who were active at work and men reporting a fair or good health status.

Table 3 shows the age-standardised rates of participation overall and in each sport and exercise grouping at each time point, the multivariate-adjusted ORs and 95\% CI for 2003-04 and 2006. Among men, there were no apparent changes over time in the age-standardised rates of any sport and exercise participation, and there were small increases in regular participation. When we adjusted for changes in covariates, there were higher ORs than 1997/98 for any and regular sport and exercise participation in both 2003/04 and 2006 (fig 1). Trends for men's participation in each sport and exercise groupings presented a mixed picture, as there were decreases in any cycling and any or regular dancing and racquet sports participation but increases in any or regular gym/fitness clubbased activities (G/FC). Among men, there was also a tendency towards decreases in any and regular swimming, running/ jogging, team sports and golf, but multivariate adjustments diminished the magnitude of the ORs.

Among women, there were clear increases over time in the rates and ORs of any and overall regular sport and exercise participation (table 3, fig 1) but decreases in any cycling and racquet sports (table 3 ). There was also a tendency towards decreases in swimming, dancing (any) and racquet sports (any/ regular) but multivariate adjustments diminished the magnitude of the ORs. Women's overall upward trend was due to increases in G/FC, running (any/regular) and martial arts (any).

Sport and exercise time trends were age group-specific. Increases for men and women aged $45-64$ years and $\geqslant 65$ years, and women aged 30-44 years were clear, but increases were less clear among men aged 30-44 years (table 4). Analysing all men aged $\geqslant 45$ years, there were increases in regular cycling (from $5.7 \%$ in $1997 / 98$ to $7.0 \%$ in 2006 ; OR $=1.37,95 \%$ CI 1.14 to $1.67, \mathrm{p}=0.005$ ), running (from $2.1 \%$ to $2.8 \%, 1.40,1.04$ to 1.89 , $\mathrm{p}=0.037$ ), racquet sports (from $1.9 \%$ to $2.7 \%, 1.55,1.14$ to 2.11 , $\mathrm{p}=0.010$ ) and $\mathrm{G} / \mathrm{FC}$ (from $8.0 \%$ to $10.6 \%, 1.38,1.17$ to 1.62 , $\mathrm{p}<0.001)$. Among women aged $\geqslant 45$ years, there were increases in regular swimming (from $5.5 \%$ in $1997 / 98$ to $7.0 \%$ in 2006 , $1.19,1.00$ to $1.41, p=0.057$ ), running (from $0.5 \%$ to $1.6 \%, 3.39$, 2.15 to $5.03, \mathrm{p}<0.001$ ) and G/FC (from $9.1 \%$ to $13.5 \%, 1.54,1.35$

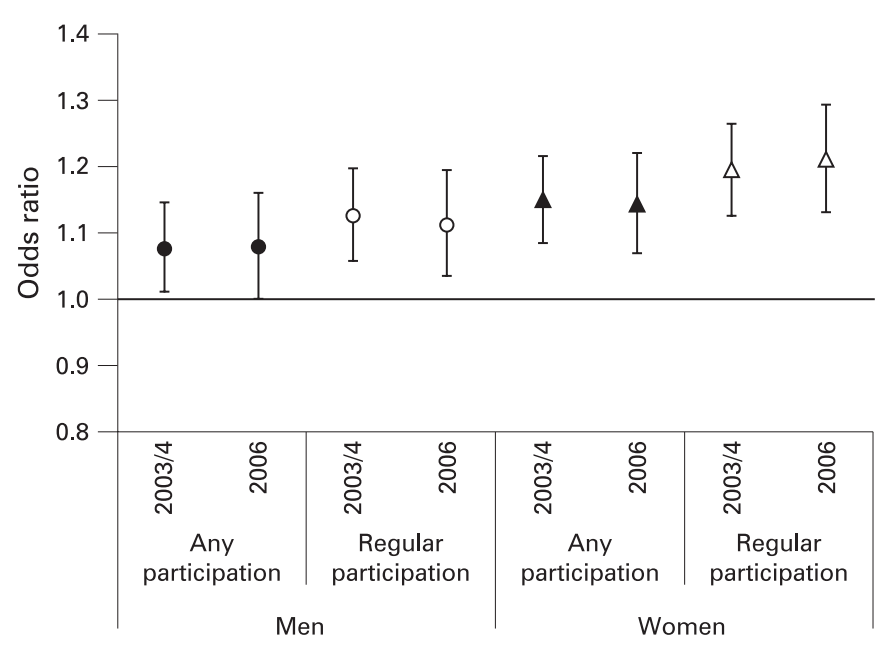

Figure 1 Age-standardised and multivariate-adjusted ORs for any and regular sports and exercise participation in 2003/04 and 2006 (compared with the 1997/98 referent time point). Adults aged $\geqslant 16$ years and over living in England. 
Table 3 Age-standardised participation rates between 1997/8 and 2006 for men and women aged $\geqslant 16$ years living in England

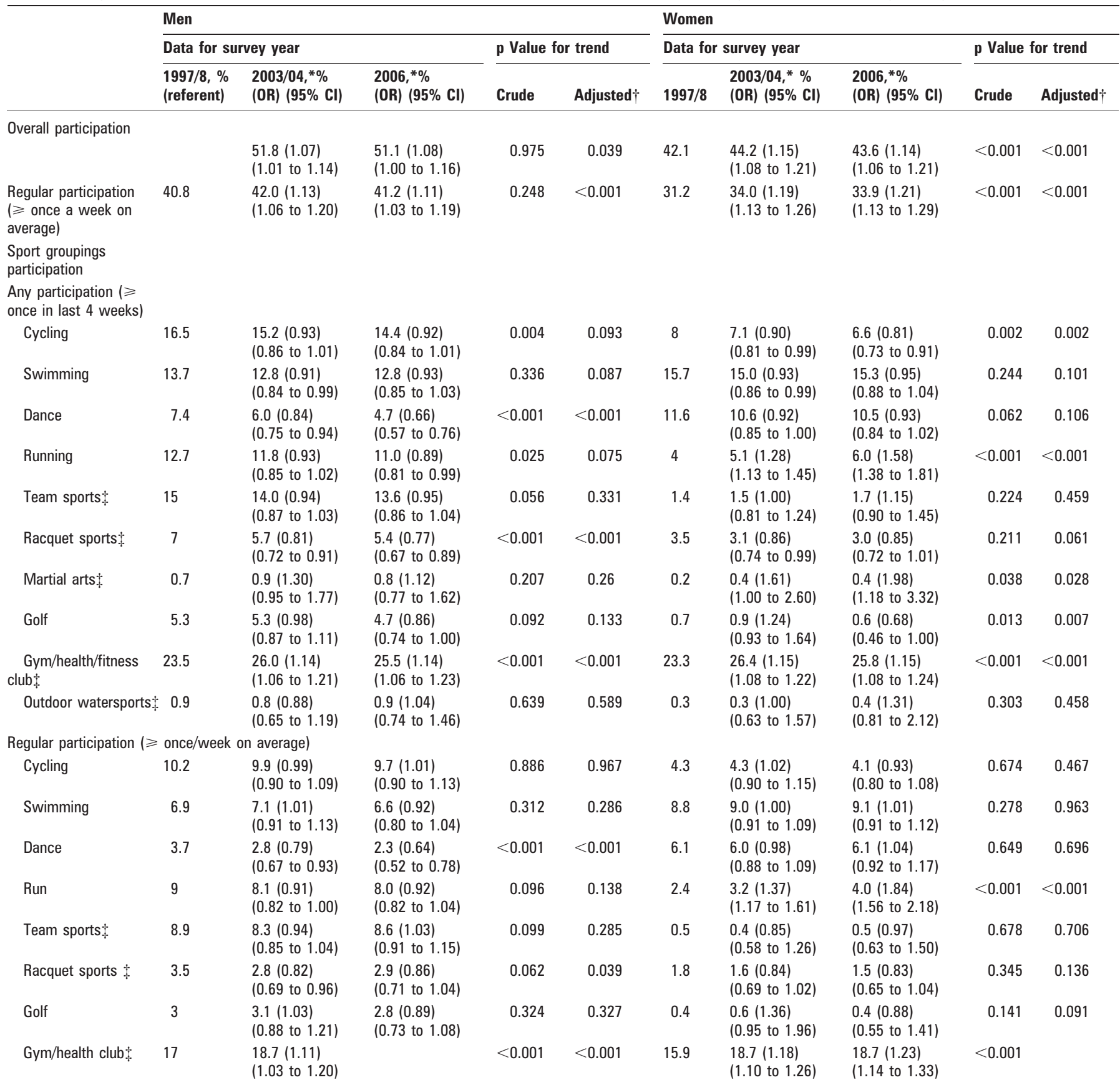

*ORs and 95\% confidence internals for comparisons with 1997/8, which was the referent time point. $†$ Age-standardised and multivariable-adjusted 0R and 95\% Cl using 1997/8 as the referent time point; adjusted for age, ethnicity, social class, income, education, obesity status, car ownership, smoking status, general health, occupational activity and nonsporting/non-occupational physical activity. $\$$ See table 1 for description of sports and exercise groupings.

to $1.76, \mathrm{p}<0.001$ ) and decreases in dancing (from 4.4 to $3.8 \%$, $0.84,0.68$ to $1.04, p=0.002$ ).

Focusing the analysis on young adults aged 16 to 29 we found that young men's multivariable ORs for regular participation in cycling in 2006, and in running, racquet sports and dancing in 2003/04 and 2006, were considerably lower than in 1997/98 (fig 2A). Among young women, the ORs for regular cycling were lower in 2006 and for running and dancing were higher in 2003/04 than 1997/98 (fig 2B). We investigated further regular participation among men in late adolescence (16-20 years). Decreases in the overall regular participation rates for this group were modest (from $72.3 \%$ in $1997 / 98$ to $69.7 \%$ in 2006 ) but the multivariable ORs were considerably lower $(\mathrm{OR}=0.71,95 \% \mathrm{CI}$
0.53 to $0.97, p=0.032$ ) compared with the $1997 / 8$ reference time point. Regular cycling for this age group decreased from $19.5 \%$ to $13.3 \%(0.60,0.41$ to $0.88, p=0.020)$, regular swimming from $9.8 \%$ to $8.9 \%(0.62,0.38$ to $1.03, p=0.098)$, dancing from $10.8 \%$ to $5.5 \%(0.59,0.35$ to $0.98, p=0.042)$, running from $25.7 \%$ to $20.1 \%(0.61,0.44$ to $0.85, \mathrm{p}<0.001)$ and team sports from $36.7 \%$ in $1997 / 98$ to $32.2 \%$ in $2003 / 04$ (0.71, 0.56 to 0.91$)$. The upward time trend in regular sport and exercise participation noted above was pronounced only among men from non-manual social classes, of white ethnic background and from higher income households (fig 3A). No differences were noted in sport and exercise participation trends by socioeconomic status or ethnicity among women (fig 3B). 
Table 4 Overall sports and exercise participation at two levels by age group

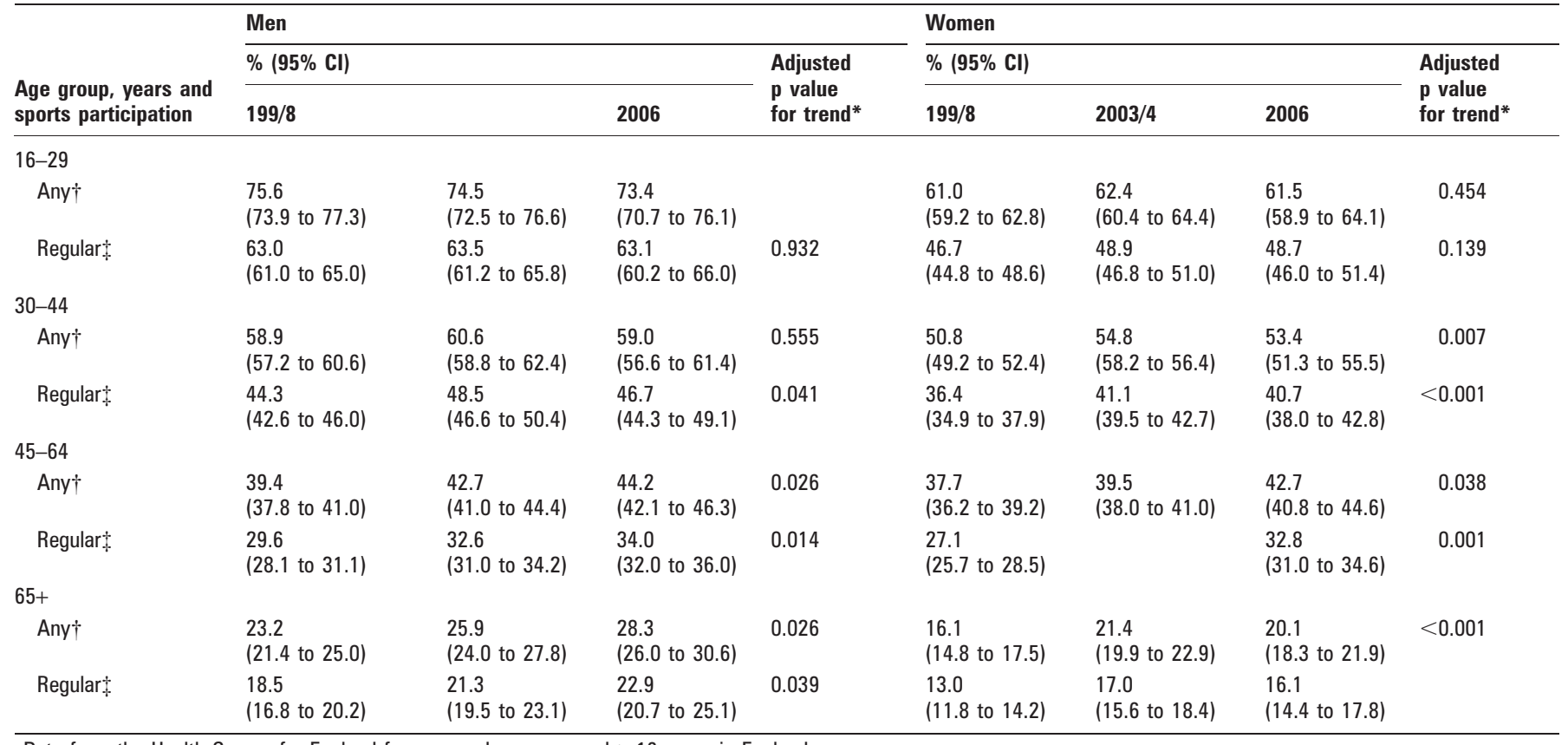

Data from the Health Survey for England for men and women aged $\geqslant 16$ years in England.

${ }^{*}$ Adjusted for ethnicity, social class, income, education, obesity status, car ownership, smoking status, general health, occupational activity and non-sporting/non-occupational physical activity. ${ }^{*}$ At least once/week on average. $†$ At least once in the last 4 weeks.

Among sport and exercise participants, the mean total weekly sport and exercise volume increased from 167 minutes per week in $1997 / 98$ (95\% CI 163 to 170 ) to 174 in 2003/04 (170 to 178) and 176 in 2006 (171 to 181$)(B=6.24,95 \%$ CI 3.34 to 9.15 , $\mathrm{t}=4.219, \mathrm{p}<0.001)$. This increase was the result of increases in the volumes of G/F (from 74 minutes in 1997/98 (72 to 76) to 85 minutes (82 to 87 ) in 2006, $\mathrm{p}<0.001)$; cycling from 76 minutes (72 to 80 ) to 88 minutes ( 82 to 93 ), $p<0.001$ ); and running (from 62 minutes in (58 to 65) to 68 minutes (63 to 72), $p=0.041)$.

\section{DISCUSSION}

To our knowledge, the present study is the first time-trend analysis of sport and exercise participation in England that takes into account temporal changes in factors that determine sports participation. The key finding is that during the decade 1997-2006, overall participation increased but the increase did not occur equally across socioeconomic, demographic and ethnic groups. The overall increases between 1997/8 and 2006 were relatively small $(<0.5 \%$ for men's and $<3 \%$ for women's regular overall sport and exercise participation) but this was due to the fact that increases in some groups were offset by decreases in other groups. As noted in a previous study, ${ }^{13}$ the rapid decreases in occupational physical activity since the early 1990s may have encouraged the uptake of other activities as a compensatory behaviour. Gym and fitness club-based activity was the grouping that showed the most consistent and noticeable increase in our sample. Market research data has shown that attendance in UK fitness, sports and leisure facilities grew from 10\% in 1991 to $14 \%$ in 2004, and regular visitors (>once/week) increased from 6\% to $13 \% .{ }^{16}$ This may be due to increased time pressures, which have led to a shift to forms of non-competitive activities that are flexible and individual in nature, such as gym workouts, aerobics and calisthenics. Our findings imply that the commonly held view that physical activity levels of the population are declining, ${ }^{17}$ often cited in public health ${ }^{5}$ and health policy documents, ${ }^{18}$ may be oversimplistic. This view is invariably based on proxy ecological evidence that does not take into account that changes in a certain domain (eg reduction in miles walked) may be counterbalanced by changes in the opposite direction for another domain, such as the increases in sport and exercise suggested by our study. The general upward trend may involve some reporting bias associated with the population's increase in health behaviour awareness. Rapid increases in obesity $^{19}$ have triggered a dramatic increase in media coverage on issues concerning fitness, exercise and dieting. ${ }^{20}$ Such phenomena may have increased the effect of social desirability bias in more recent years, contributing to the upward sport and exercise trend we observed. Another potential source of response bias may be the decline in survey response rates-for example, respondents may be more likely to be participants in sport and exercise than are non-respondents. For example, people from lower social classes are less likely to be participate in sport and more likely to be non-responders in survey research. ${ }^{21} 22$ We dealt with such a possibility by adjusting all our analyses for several socioeconomic status indicators.

Comparisons with other studies are difficult, as no other nationwide population survey has used consistent methodology to assess trends in sports up to 2006. An unadjusted reanalysis of GHS found a decrease in any sports participation from $46 \%$ in 1996 to $43 \%$ in 2002, with the decreases being slightly greater for men. ${ }^{11}$ However, these data are limited by changes in the 2002 measuring techniques, which may have affected the direction and magnitude of the trend. ${ }^{23}$

Our results may be useful for designing interventions to increase sports participation in the run-up to the 2012 London Olympics. Relevant policy documents ${ }^{24}$ suggest that the Olympics will act as an inspiration to people, increasing their participation in sport, and similar statements have repeatedly been made by prominent politicians. ${ }^{25}$ However, an independent report on the London Olympics legacy ${ }^{26}$ concluded that such an 

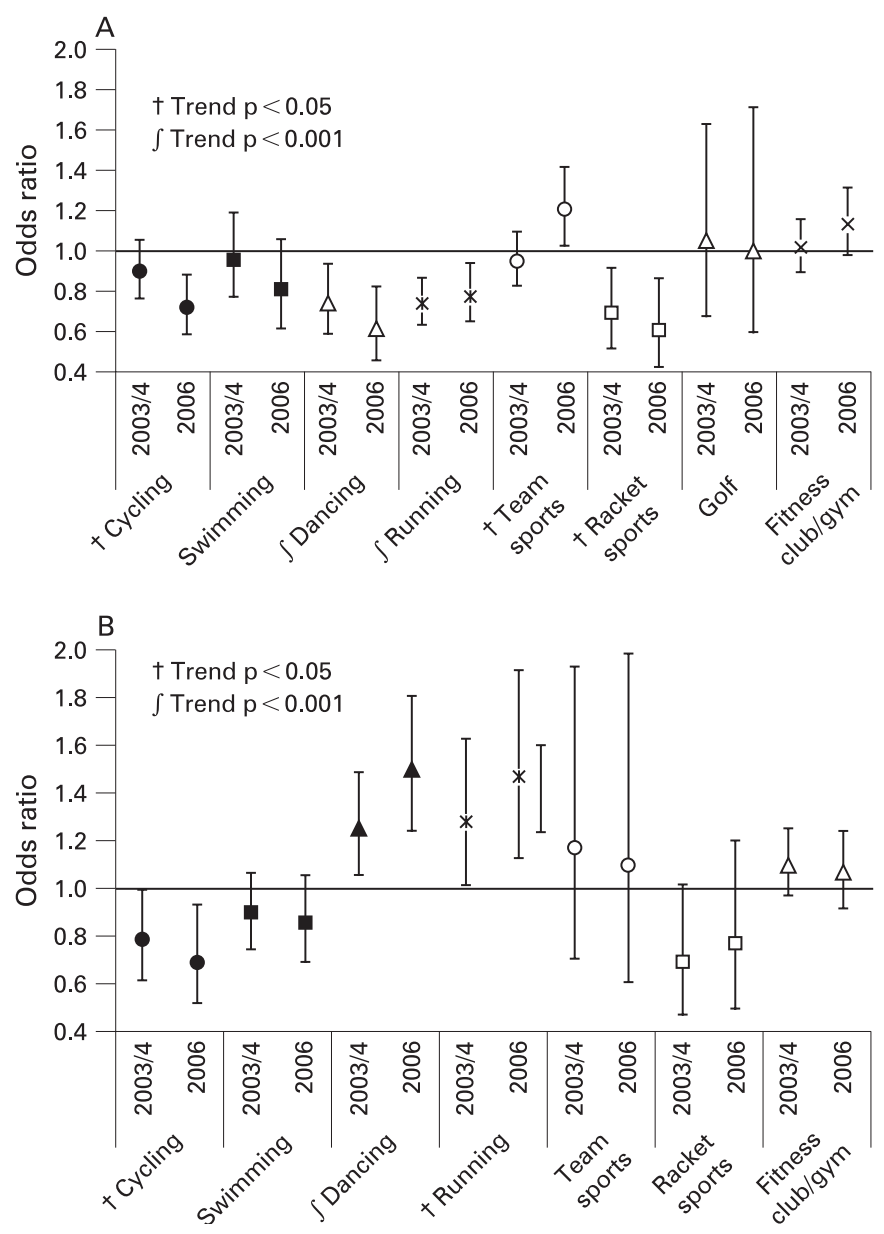

Figure 2 Multivariatble-adjusted ORs for regular participation in sport and exercise groupings in 2003/2004 and 2006 (compared with the 1997/98 referent time point) for (A) men and (B) women aged 16-29 years living in England.

expectation is unsubstantiated. Our results offer some support for such a conclusion by enabling us to make comparison in participation between before the successful London bid (2003/ 04) and 1 year immediately after (2006); participation in major Olympic sports (swimming, cycling, running and team and racquet sports) among young men, the population group that is most likely to adopt role models from the world of sports, ${ }^{26}$ showed signs of decrease. On the other hand, it is encouraging that the gap in participation between men and women has narrowed since 1997/98 as women's participation has considerably increased among most female population groups. It is also encouraging that although overall participation remains low among middle-aged and older adults, both any and regular participation increased consistently by approximately $4-5 \%$ among respondents aged $\geqslant 45$ years. The decreases in cycling we found have been previously reported; ${ }^{11}{ }^{27}$ however, our data showed that such decreases are not universal across the population, as the ORs for regular cycling participation among men aged $\geqslant 45$ years has increased by $38 \%$ in 2006 compared with 1997/98. Such findings may be linked to the greater health awareness and wider dissemination of the chronic diseasepreventing qualities of exercise, which are more apparent in later life, motivating more people from these age groups to uptake sport and exercise. We speculate that increases in education levels (table 1) and access to information, eg through expanded internet access ${ }^{28}$ may play a role.
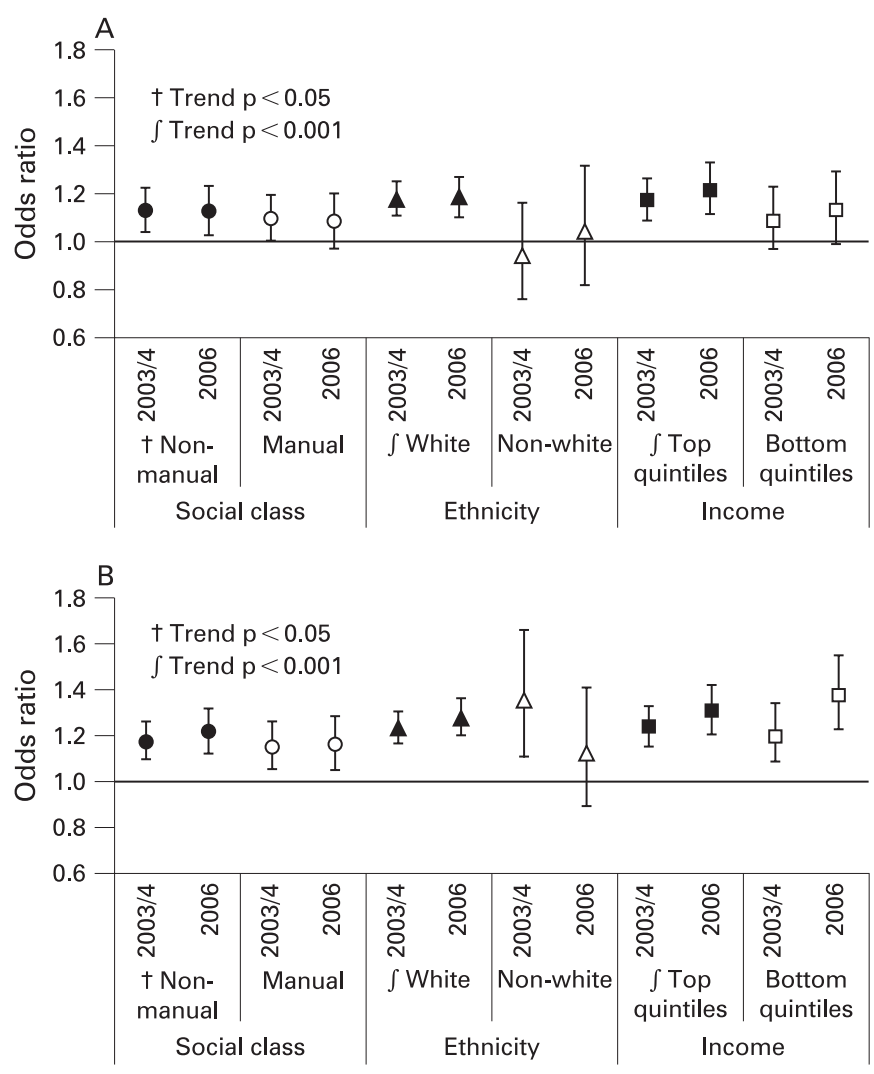

Figure 3 Age-standardised ORs for regular sports and exercise participation in 2003/2004 and 2006 (compared with the 1997/98 referent time point) for (A) men and (B) women aged $16-29$ years living in England.

Among men there seem to be some socioeconomic and agerelated variation in the participation trends. The most apparent aspect of this element is the marked decrease in many popular activities (eg cycling, running, racquet sports) among young men ( $<30$ years) and particularly among men in late adolescence. This is particularly alarming, considering that physical activity habits acquired in adolescence not only not only continue into later adult life but may also have consequences for adult health. ${ }^{29}$ Another cause of concern is that the previously documented gap between men from lower and higher socioeconomic strata ${ }^{12}$ and white and non-white ethnic backgrounds ${ }^{30}$ seems to be widening.

The strengths of the study include the up-to-date information covering up to 2006, the large, nationally representative samples, the high survey response rates, the continuous data collection that eliminates seasonality bias, the presentation of age-standardised data, and the adjustment of our results for a plethora of socioeconomic, demographic and non-sporting physical activity variables. The study limitations include the use of self-reported physical activity measures, which are potentially prone to recall and response bias. The cycling questions enquired about cycling for any purpose and we were therefore unable to investigate trends in recreational (non-transport) cycling which is the focus of our paper. The decline in survey response rates over time may have introduced response bias in the more recent surveys and this may have affected the time trends examined by our study. Finally, our results are limited by the lack of sufficient statistical power to examine more in-depth time trends within non-white adults, a population with markedly low sports participation. ${ }^{30}$ 


\section{What is already known on this topic}

- Previous publications examining time trends in participation in recreational sports and exercises in England are confounded by methodological limitations and do not take into account wider socioeconomic, demographic and behavioural changes occurring during the same period of time.

- Some data show that adults' sports participation in England has decreased and some show that it has increased between early to mid 1990s and early to mid 2000s.

\section{What this study adds}

- When a range of socioeconomic, demographic and behavioural changes are taken into account, overall participation in recreational sports and exercises in England increased between 1997 and 2006 but changes in participation over time were specific for age, socioeconomic status and ethnic background.

- The upward trend is apparent only among middle-aged and older adults and young men's participation in many popular activities such as cycling, swimming, running and racquet sports showed marked decreases.

- There are no signs that the gap in participation between lower and higher socioeconomic strata and between white and ethnic minority groups is narrowing.

\section{CONCLUSION}

Our results are encouraging in that overall sport and exercise participation in England has increased between 1997 and 2006. This increase is independent of other socioeconomic, demographic and behavioural changes in the population. The most apparent increases have occurred in participation in individual activities that are commonly performed in gyms and fitnessclub environments. The overall increase seems to be the result of increases among middle-aged and older adults, whereas the opposite is true for younger men, where there have been substantial decreases in many common sports. Another cause of concern is that there are no signs that the gap between high and low socioeconomic groups and white and non-white ethnic groups is narrowing. Sport-promoting and health policy efforts should focus on these groups and try to expand participation. A better understanding of the mechanisms behind the "success story" of middle-aged and older adults through health and sport policy research may assist such efforts.

Acknowledgements: We would like to thank Dr M Hillsdon and Dr N Shelton for commenting on the manuscript. The Health Survey for England was funded by the English Department of Health/Health and Social Care Information Centre (the data presented here are available from the UK Data Archive (http://www.data-archive.ac. uk/findingData/hseTitles.asp).

Funding: ES is funded by the National Institute for Health Research.

Competing interests: ES is an academic advisor for the Active People Survey, which is funded by Sport England. One of the aims of this survey is the tracking of time trends in sports and exercise participation of adults living in England.

\section{REFERENCES}

1. Kohl HW III. Physical activity and cardiovascular disease: evidence for a dose response. Med Sci Sports Exercise 2001;33:S472-83.

2. Lynch J, Helmrich SP, Lakka TA, et al. Moderately intense physical activities and high levels of cardiorespiratory fitness reduce the risk of non-insulindependent diabetes mellitus in middle-aged men. Arch Intern Med 1996;156:1258-354.

3. Tune I, Furberg AS. Physical activity and cancer risk: dose-response and cancer all sites and specific sites. Med Sci Sports Exercise 2001;33:S530-50.

4. Wareham N. Physical activity and obesity prevention. Obesity Reviews 2007:8(suppl):109-14.

5. Department of Health. At least five a week: evidence on the impact of physical activity and its relationship to health: report from the Chief Medical Officer. London: The Stationery Office, 2004.

6. Swain DP, Franklin BA. Comparison of Cardioprotective benefits of vigorous verses moderate intensity aerobic exercise. Am J Cardiol 2006;97:141-7.

7. Hassmén P, Koivula N, Uutela A. Physical exercise and psychological well-being: a population study in Finland. Prev Med 2000;30:17-25.

8. Steptoe A, Butler N. Sports participation and emotional wellbeing in adolescents. Lancet 1996:347:1789-92

9. Renewal.net. Sport, Physical Activity and Renewal: Case studies. London: renewal.net, 2005. http://www.sportdevelopment.org.uk/renewalnetsport.pdf

10. Sport England. The Active People Survey. http://www.sportengland.org/index/ get resources/research/active people.htm

11. Sport England. Participation in sports in Great Britain: trends 1987 to 2002. London: Sport England 2005

12. Health and Social Care Information Centre. The Health Survey for England 2006 : CVD and risk factors adults, obesity and risk factors children. http://www.ic.nhs.uk/ pubs/HSE06CVDandriskfactors (accessed 26 May 2008).

13. Stamatakis $\mathbf{E}$, Ekelund U, Wareham NJ. Temporal trends in physical activity in England: the Health Survey for England 1991 to 2004. Prev Med 2007:45:416-23.

14. Health and Social Care Information Centre. The Health Survey for England 2006 Volume 3: methodology and documentation. http://www.ic.nhs.uk/webfiles/ publications/HSE06/HSEO6 VOL3.pdf (accessed 26 May 2008).

15. Stamatakis E, Hillsdon M, Primatesta P. Domestic physical activity in relationship to multiple CVD risk factors. Am J Prev Med 2007:32:257-60.

16. Mintel International Group Ltd. Leisure centres and swimming pools - UK London: Mintel International Group Ltd, 2004.

17. Prentice AM, Jebb SA. Obesity in Britain: gluttony or sloth? BMJ 1995;311:437-9

18. Health Select Committee. Third Report of Session 2003-04, Obesity HC23-1. London: The Stationery Office, 2004. http://www.parliament.the-stationery-office.co. uk/pa/cm200304/cmselect/cmhealth/23/2302.htm (accessed 26 May 2008).

19. Health Survey for England 2006. Latest trends. http://www.ic.nhs.uk/pubs/ hse06trends (accessed 26 May 2008).

20. International Food Information Council Foundation. Trends in obesity-related media coverage. http://www.ific.org/research/obesitytrends.cfm (accessed 26 May 2008).

21. Turrell G, Patterson C, Oldenburg B, et al. The socio-economic patterning of survey participation and non-response error in a multi-level study of food purchasing behaviour: area- and individual-level characteristics. Public Health Nutr 2002:6:181-9.

22. Department of Health. The Health Survey for England 1994. Volume II: survey methodology and documentation, London: The Stationery Office, 1995.

23. Welk GJ. Introduction to physical activity research. In: Welk GJ, ed. Physical activity assessments for health-related research. Champaign, IL: Human Kinetics, 2002.

24. Sports England. The London Plan for sport and physical activity: working for an active and successful sporting capital 2004-2008. London: Sports England, 2004.

25. Jowell T. International Olympic Committee presentation in Athens by London 2012, 15 August 2004: http://www.culture.gov.uk/Reference library/ Press_notices/archive_2004/dcms_speech_15_August_2004.httm laccessed 20 February 20 2008).

26. Coulter F. Stuck in the blocks? a sustainable sporting legacy. In: Vigor A, Mean M, Tims C, eds. After the gold rush. a sustainable Olympics for London. London: Institute for Public Policy Research and DEMOS, 2004.

27. Department of Transport. Transport trends: 2004 edition. London: Department of Transport, 2004. http://www.dft.gov.uk/stellent/groups/dft transstats/documents/ downloadable/dft transstats 035650.pdf (accessed 26 May 2008).

28. http://www.statistics.gov.uk/cci/nugget.asp?id = 8 (accessed 26 May 2008).

29. Hallal P, Cesar V, Azevedo Mario, Wells J. Adolescent Physical Activity and Health: A Systematic Review. Sports Medicine 2006;12:1019-30.

30. Stamatakis E. Physical activity. In: Craig R, Mindell J, eds. The Health Survey for England 2004. The health of minority ethnic groups. London: The Stationary Office, 2006 


\section{CORRECTION}

There was an error in the pagination of the articles published in the October and November 2008 issues of the journal. Please see a corrected list of citations below. The journal apologises for this error.

Khan KM. Preventing ACL injuries, turning research into practice and avoiding media ambush. Br J Sports Med 2008;42:483-4. should be Khan KM. Preventing ACL injuries, turning research into practice and avoiding media ambush. $\mathrm{Br} J$ Sports Med 2008;42:783-4.

Gregory PL, Seah R, Pollock N. What to tell the media-or not: consensus guidelines for sports physicians. $\mathrm{Br} J$ Sports Med 2008;42:485-8. should be Gregory PL, Seah R, Pollock N. What to tell the media-or not: consensus guidelines for sports physicians. $\mathrm{Br} J$ Sports Med 2008;42:785-8.

Fagan V, Delahunt E. Patellofemoral pain syndrome: a review on the associated neuromuscular deficits and current treatment options. Br J Sports Med 2008;42:489_ 95. should be Fagan V, Delahunt E. Patellofemoral pain syndrome: a review on the associated neuromuscular deficits and current treatment options. Br J Sports Med 2008;42:789-95.

Beltrami FG, Hew-Butler T, Noakes TD. Drinking policies and exercise-associated hyponatraemia: is anyone still promoting overdrinking? Br J Sports Med 2008;42:496501. should be Beltrami FG, Hew-Butler T, Noakes TD. Drinking policies and exerciseassociated hyponatraemia: is anyone still promoting overdrinking? $\mathrm{Br} J$ Sports Med 2008;42:796-801.

Diehl JJ, Pirozzolo JJ, Best TM. The practice of primary care sports medicine in the USA. Br J Sports Med 2008;42:506-9. should be Diehl JJ, Pirozzolo JJ, Best TM. The practice of primary care sports medicine in the USA. Br J Sports Med 2008;42:806-8.

Hides J, Stanton W, Freke M, et al. MRI study of the size, symmetry and function of the trunk muscles among elite cricketers with and without low back pain. Br J Sports Med 2008;42:509-13. should be Hides J, Stanton W, Freke M, et al. MRI study of the size, symmetry and function of the trunk muscles among elite cricketers with and without low back pain. $\mathrm{Br} J$ Sports Med 2008;42:809-13

Kukidome T, Shirai K, Kubo J, et al. MRI evaluation of body composition changes in wrestlers undergoing rapid weight loss. $\mathrm{Br} \mathrm{J}$ Sports Med 2008;42:514-18. should be Kukidome T, Shirai K, Kubo J, et al. MRI evaluation of body composition changes in wrestlers undergoing rapid weight loss. $\mathrm{Br} J$ Sports Med 2008;42:814-18.
Zhang Y, Lin Z, Hu Y, et al. Effect of Ganoderma lucidum capsules on $T$ lymphocyte subsets in football on "living hightraining low". Br J Sports Med 2009;42: 519-22. should be Zhang Y, Lin Z, Hu Y, et al. Effect of Ganoderma lucidum capsules on T lymphocyte subsets in football on "living high-training low". $\mathrm{Br} J$ Sports Med 2009;42:819-22.

Edwards AM, Wells C, Butterly R. Concurrent inspiratory muscle and cardiovascular training differentially improves both perceptions of effort and $5000 \mathrm{~m}$ running performance compared with cardiovascular training alone. $\mathrm{Br} J$ Sports Med 2009;42:523-7. should be Edwards AM, Wells C, Butterly R. Concurrent inspiratory muscle and cardiovascular training differentially improves both perceptions of effort and $5000 \mathrm{~m}$ running performance compared with cardiovascular training alone. $\mathrm{Br} J$ Sports Med 2009;42:823-7.

Baron B, Noakes TD, Dekerle J, et al. Why does exercise terminate at the maximal lactate steady state intensity? $\mathrm{Br} J$ Sports Med 2008;42:528-33. should be Baron B Noakes TD, Dekerle J, et al. Why does exercise terminate at the maximal lactate steady state intensity? $\mathrm{Br} J$ Sports Med 2008;42:828-33.

Ogai R, Yamane M, Matsumoto $\mathrm{T}$, et al. Effects of petrissage massage on fatigue and exercise performance following intensive cycle pedalling. $\mathrm{Br} J$ Sports Med 2008;42:534-8. should be Ogai R, Yamane M. Matsumoto $T$, et al. Effects of petrissage massage on fatigue and exercise performance following intensive cycle pedalling. $\mathrm{Br} J$ Sports Med 2008;42:834-8.

Sandrock M, Schulze C, Schmitz D, et al. Physical activity throughout life reduces the atherosclerotic wall process in the carotid artery. Br J Sports Med 2008;42:539-44. should be Sandrock M, Schulze C, Schmitz D, et al. Physical activity throughout life reduces the atherosclerotic wall process in the carotid artery. $\mathrm{Br} J$ Sports Med 2008;42:839-44.

Ferrari M, Bonella F, Benini L, et al. Acid reflux into the oesophagus does not influence exercise-induced airway narrowing in bronchial asthma. $\mathrm{Br} J$ Sports Med 2008;42:545-9. should be Ferrari M Bonella F, Benini L, et al. Acid reflux into the oesophagus does not influence exerciseinduced airway narrowing in bronchial asthma. Br J Sports Med 2008;42:845-9.

Randolph CC. Commentary on Acid reflux into the oesophagus does not influence exercise-induced airway narrowing in bronchial asthma. Br J Sports Med 2008:42:549_ 50. should be Randolph CC. Commentary on Acid reflux into the oesophagus does not influence exercise-induced airway narrowing in bronchial asthma. $\mathrm{Br} J$ Sports Med 2008;42:849-50.
Bradshaw CJ, Bundy M, Falvey E. The diagnosis of longstanding groin pain: a prospective clinical cohort study. $\mathrm{Br} J$ Sports Med 2008;42:551-4. should be Bradshaw CJ, Bundy M, Falvey E. The diagnosis of longstanding groin pain: a prospective clinical cohort study. $\mathrm{Br} J$ Sports Med 2008;42:851-4.

Zoumalan CI, Blumenkranz MS, McCulley TJ, et al. Severe surfing-related ocular injuries: the Stanford Northern Californian experience. Br J Sports Med 2008;42:555-7. should be Zoumalan CI. Blumenkranz MS, McCulley TJ, et al. Severe surfing-related ocular injuries: the Stanford Northern Californian experience. $\mathrm{Br} I$ Sports $\mathrm{Med}$ 2008;42:855-7.

Banffi G, Krajewska M, Melegati G, et al. Effects of whole-body cryotherapy on haematological values in athletes. $\mathrm{Br} J$ Sports Med 2008;42:558. should be Banffi G Krajewska M, Melegati G, et al. Effects of whole-body cryotherapy on haematological values in athletes. $\mathrm{Br} J$ Sports Med 2008;42:858.

Schwellnus $\mathbf{M}$. SportsMedUpdate. $\mathrm{Br} J$ Sports Med 2008;42:559-60. should be Schwellnus M. SportsMedUpdate. $\mathrm{Br} J$ Sports Med 2008;42:859-60.

Khan KM. Debating transversus abdominis, the "exercise pill" and whether flying limits athletes' performance on arrival. Br J Sports Med 2008;42:561. should be Khan KM Debating transversus abdominis, the "exercise pill" and whether flying limits athletes' performance on arrival. $\mathrm{Br} J$ Sports $\mathrm{Med}$ 2008;42:861.

Warden SJ, Fuchs RK. Are "exercise pills" the answer to the growing problem of physical inactivity? $\mathrm{Br} J$ Sports Med 2008;42:562-3. should be Warden SJ Fuchs RK. Are "exercise pills" the answer to the growing problem of physical inactivity? Br J Sports Med 2008;42:862-3

Cook J. Jumping on bandwagons: taking the right clinical message from research. $\mathrm{Br} J$ Sports Med 2008;42:563. should be Cook J. Jumping on bandwagons: taking the right clinical message from research. $\mathrm{Br} J$ Sports Med 2008;42:863.

Kuipers H, Van't Hullenaar GAC, Pluim BM, et al. Four weeks' corticosteroid inhalation does not augment maximal power output in endurance athletes. $\mathrm{Br} J$ Sports Med 2008;42:568-71. should be Kuipers H, Van't Hullenaar GAC, Pluim BM, et al. Four weeks' corticosteroid inhalation does not augment maximal power output in endurance athletes. $\mathrm{Br} J$ Sports Med 2008;42 868-71.

du Toit C, Stieler M, Saunders R, et al Diagnostic accuracy of power Doppler ultrasound in patients with chronic tennis elbow. Br J Sports Med 2008;42:572-6. should be du Toit C, Stieler M, Saunders R, et al. 
Diagnostic accuracy of power Doppler ultrasound in patients with chronic tennis elbow. Br J Sports Med 2008;42:872-6.

Geertsema C, Williams AB, Dzendrowskyj $\mathrm{P}$, et al. Effect of commercial airline travel on oxygen saturation in athletes. $\mathrm{Br} J$ Sports Med 2008;42:577-81. should be Geertsema C, Williams AB, Dzendrowskyj $\mathrm{P}$, et al. Effect of commercial airline travel on oxygen saturation in athletes. $\mathrm{Br} J$ Sports Med 2008;42:877-81.

Gratze G, Mayer H, Luft FC, et al. Determinants of fast marathon performance: low basal sympathetic drive, enhanced postcompetition vasodilation and preserved cardiac performance after competition. Br J Sports Med 2008;42:582-8. should be Gratze G, Mayer H, Luft FC, et al. Determinants of fast marathon performance: low basal sympathetic drive, enhanced postcompetition vasodilation and preserved cardiac performance after competition. Br J Sports Med 2008;42:882-8.

Bessa A, Nissenbaum M, Monteiro A, et al. High-intensity ultraendurance promotes early release of muscle injury markers. $\mathrm{Br} J$ Sports Med 2009;42:589-93. should be Bessa A, Nissenbaum M, Monteiro A, et al. Highintensity ultraendurance promotes early release of muscle injury markers. $\mathrm{Br} J$ Sports Med 2009;42:889-93.

Borrione P, Rizzo M, Spaccamiglio A, et al. Sport-related hyperhomocysteinaemia: a putative marker of muscular demand to be noted for cardiovascular risk. Br J Sports Med 2008;42:594-600. should be Borrione P, Rizzo M, Spaccamiglio A, et al. Sport-related hyperhomocysteinaemia: a putative marker of muscular demand to be noted for cardiovascular risk. $\mathrm{Br} J$ Sports $\mathrm{Med}$ 2008;42:894-900.

Stamatakis E, Chaudhury M. Temporal trends in adults' sports participation patterns in England between 1997 and 2006: the Health Survey for England. Br J Sports Med 2008;42:601-8. should be Stamatakis E, Chaudhury M. Temporal trends in adults' sports participation patterns in England between 1997 and 2006: the Health Survey for England. $\mathrm{Br} J$ Sports Med 2008;42: 901-8.

Nichols AW. Sports medicine clinical trial research publications in academic medical journals between 1996 and 2005: an audit of the PubMed MEDLINE database. Br J Sports Med 2008;42:609-21. should be Nichols AW. Sports medicine clinical trial research publications in academic medical journals between 1996 and 2005: an audit of the PubMed MEDLINE database. Br J Sports Med 2008;42:909-21.

Shimada H, Suzuki T, Kimura Y, et al. Effects of an automated stride assistance system on walking parameters and muscular glucose metabolism in elderly adults. $\mathrm{Br} J$ Sports Med 2008;42:622-29. should be
Shimada H, Suzuki T, Kimura Y, et al. Effects of an automated stride assistance system on walking parameters and muscular glucose metabolism in elderly adults. $\mathrm{Br} J$ Sports Med 2008;42:922-9.

Allison GT, Morris SL. Transversus abdominis and core stability: has the pendulum swung? Br J Sports Med 2008;42:630-1. should be Allison GT, Morris SL Transversus abdominis and core stability: has the pendulum swung? Br J Sports Med 2008;42:930-1.

Kasahara S, Mashiko H, Niwa S-I. Superior performance in WAIS-R block design among top-level rugby players. $\mathrm{Br} J$ Sports Med 2008;42:632-3. should be Kasahara S, Mashiko H, Niwa S-I. Superior performance in WAIS-R block design among top-level rugby players. $\mathrm{Br} J$ Sports Med 2008;42: 932-3.

Blatteau J-E, Pény C, Pontier J-M, et al. Influence of repetitive open sea dives and physical exercises on right-to-left shunting in healthy divers. $\mathrm{Br} J$ Sports Med 2009;42:634-6. should be Blatteau J-E, Pény C, Pontier J-M, et al. Influence of repetitive open sea dives and physical exercises on right-to-left shunting in healthy divers. Br J Sports Med 2009;42:934-6.

Schwellnus M. SportsMedUpdate. $\mathrm{Br} J$ Sports Med 2008;42:637-8. should be Schwellnus M. SportsMedUpdate. $\mathrm{Br} J$ Sports Med 2008;42:937-8. 